\title{
Desirable Characteristics of an Ideal Online Learning Environment
}

\author{
Rusen Meylani \\ Gary Bitter \\ Jane Legacy \\ Arizona State University \\ Email: rmeylani@asu.edu
}

\section{Doi:10.5901/jesr.2015.v5n1p203}

\section{Abstract}

\begin{abstract}
The latest advances in Internet and multimedia have increased the popularity of online learning environments. Although every new online learning environment (OLE) claims to have introduced one or more novelties, not every OLE is successful in creating a long and lasting impact in learners' knowledge. In this article, we have analyzed the recent research literature relevant to online and e-learning as well as computer based instruction with the purpose of identifying the desirable characteristics of an ideal new generation OLE. Ultimately, this research aims to serve as a guideline for the creators of the existing and novel OLE's for superior teaching and learning experiences.
\end{abstract}

Keywords: Online learning environment, e-learning, computer based instruction, desirable characteristics of online learning

\section{Introduction}

Research has shown that computer assisted instruction can be an effective method for teaching and learning (Fouts, 2000; Kulik, 2002; Handal et al., 2003; Maag, 2004). Computer based learning has been identified to have a positive impact on student attitudes toward technology use as well as what they learn (Aivazidis et al., 2006; Tamim et al., 2011). However, not every e-learning environment can present similar positive effects.

Online learning is defined as learning that is completely or partially accomplished through the Internet. This review is not limited to any subject area in particular. Rather, we aimed to explore and present the research that elaborates aspects of online, e- and computer based instruction that play into the improvement of teaching and learning. In this respect, we methodically investigated the recent research literature through a number of empirical studies on the subject: We compared pure and mixed online learning, elaborated the prevailing characteristics of online learning environments in terms of better teaching and learning experience, explained the concepts of the fidelity of implementation and professional development both of which are essential to utilize an OLE effectively and with high levels of implementation fidelity. We also elucidated that online learning may improve knowledge retention by employing innovative instructional models.

In the next section we will elaborate the characteristics of online, e- and computer based instruction and try to extract the desirable characteristics by restating or modifying them. Whenever we come up with such a characteristic, we will highlight it in a frame, possibly with references.

\section{Desirable Characteristics of Online Learning Environments}

Based on the findings of the studies depicted in detail within this literature review, the following can be deduced in terms of the prevailing characteristics of online and e-learning and/or computer based instruction:

\subsection{Computer tutorials and online learning activities}

Computer tutorials and online learning activities have the capacity to make students learn at their own convenience in terms of pace and level. They also receive immediate feedback while working in a learning environment that is studentcentered (Inan et al., 2010). 
Feedback is important for the brain. When a student is given feedback on an incorrect response, a number of neural processes and brain activities are triggered; the comments given by the feedback will reinforce to correct the information. In addition, a positive feedback is an indication that learning has indeed taken place encouraging the student to keep working on more the material regardless of its level of difficulty. This ideal structure of a curriculum challenges but does not frustrate students (Luo et al., 2005; Marzano et al., 2004).

Moreover, online learning has long been identified as a strategy of improved teaching-learning practices (Marzano et al., 2004). Interestingly, longitudinal studies and meta-analyses have shown that computer-based training programs are particularly effective in increasing a student's performance on standardized tests (Sivin-Kachala et al., 2000).

This confirms what is already known about the synaptic connections within the human brain and how it facilitates learning. For example, through intensive practice via online tutorials, mathematical facts are recovered easily and performed at the point of automaticity. This results in the brain spending more energy to move to the next level in terms of acquiring new mathematical skills and knowledge. In all, computer tutorials have a positive impact on the retention of old knowledge and acquisition of new knowledge (Salimpoor et al., 2010).

Therefore it follows that:

\begin{abstract}
Desirable Characteristic 1: Computer tutorials and online learning activities have the capacity to make students learn at their own convenience in terms of pace and level and have a positive impact on the retention of old knowledge and acquisition of new knowledge (Salimpoor et al., 2010). Therefore, the ideal OLE must utilize computer tutorials and online learning activities.
\end{abstract}

\title{
2.2 Use of multimedia elements, simulations and manipulatives
}

A number of studies investigated the effects of multimedia elements, simulations and manipulatives within online environments (McKethan et al., 2003; Schmeeckle, 2003; Maag, 2004; Schroeder, 2006; Zhang et al., 2006; Schnitman, 2007; Schutt, 2007; Tantrarungroj, 2008). These studies discovered two important aspects regarding multi-media components within an OLE: (1) Incorporating media components alone is not sufficient by itself to enhance instruction and positively influence learning while they contribute to knowledge retention and (2) how these media components are integrated does play a key role in student learning, e.g. when they are interactive.

Schnitman (2007) found no added effects on learning from adding extra media to online instruction; the researcher wanted to find out whether or not improving colors, navigation options and text with graphics would have an effect on the learning outcomes. The author allocated students randomly to situations in a web-based learning environment. The control group accessed the environment through a plain text-based interface, whereas the treatment group accessed through an enhanced color scheme with added graphics and navigational options. No significant differences were found by Schnitman (2007) in learning outcomes between the control and treatment groups.

Regardless of type, media elements serve as a transmission medium of material. Therefore they are doubtful to influence learning per se as indicated by the fact that a majority of these studies that did not really find any major differences in learning due to media types (Clark, 1983, 1994).

Tantrarungroj (2008) did find optimistic effects caused by added media components; the researcher distinguished between two teaching approaches for a neuroscience course taught to undergraduate computer science students. The researcher compared a controlled situation where the students in the control group were not given access to streaming video to an experimental situation where the students in the treatment group were introduced to embedded videos and online text with static graphics. The researcher did not find any significant differences between the two groups of students on a post-test that was conducted immediately after the class. However, the experimental group scored significantly higher on a knowledge retention test conducted after four weeks of the intervention which showed that the added media contributed to the retention of knowledge.

Zhang et al. (2006) proposed that how a medium is utilized is far more important than just having access to it. For instance, the researchers discovered that video enhances learning when the learner possesses the capability to interact with it, i.e. "interactive videos" do have positive impacts on learning. The authors used four situations during the study: three online environments with non-video, non-interactive video and interactive video in addition to a face-to-face situation. The students were randomly assigned to one of these groups. It was found that the performance of students within the interactive video group was significantly better than the performance of students in the three other situations whereas no statistically significant differences were found between the other three groups (non-interactive video, no video and face-to-face instruction).

Castaneda (2008) distinguished between two simulation situations for undergraduate psychology students in an 
online information technology course; one situation assisted the interaction of students with the simulation and the other situation had no simulation component. Moreover Castaneda maneuvered the arrangement of instructional activities, along with the interface of simulation appearing either before or after the achievement of expository section of the instructional course. Statistically significant positive gains were obtained by students from pre-test to post-test scores when simulations were employed.

Loar (2007), on the other hand, discovered contrasting findings for nurse practitioner candidates on their analytical abilities and problem-solving techniques. Two groups of students participated in a computer based study and each group obtained similar online instructions, along with a computer-stimulated case study for one group and an online text-based case study for the other. No significant differences were discovered among the groups obtaining text-based case study versus the group obtaining computer-stimulated version.

On the other hand, the use of manipulatives motivates and influences many students especially in mathematics education. Integration of virtual manipulatives in lectures can enhance the accomplishments of students in mathematics (Battle, 2007). Students can be engaged in creative thinking through hands-on activities as they work to discover and ultimately learn principles of math (Waite-Stupiansky and Stupiansky 1998). The process in which the students can advance to meaning by doing something is known as guided discovery. Actions and words are combined together to develop a significant synergy while they try to recall their a priori knowledge in later years. With the use of hands-on activities in mathematics lectures students can develop significant meaning about numbers and systems and get a learning experience that becomes multi-sensory. Integration of the use of manipulatives produces an opportunity that can outreach many students addressing diverse learners. Use of mnemonic devices has been employed several times in order to memorize facts about math, but students have difficult time in recalling the knowledge when they disconnect from meaning and understanding. The abilities built from the employment of manipulatives assist in facilitating the students by helping them in remembering what they did, instead of pushing them into recalling what they tried to remember. Students are more likely to observe relationships and patterns if they are engaged in guided discoveries using manipulatives on paper, hands-on or online (Simpson 1998).

Therefore it follows that:

Desirable Characteristic 2: A number of studies discovered that incorporating media components may contribute to knowledge retention but how these media components are integrated does play a key role in students' learning, e.g. when they are interactive. (McKethan et al., 2003; Schmeeckle, 2003; Maag, 2004; Schroeder, 2006; Zhang et al., 2006; Schnitman, 2007; Schutt, 2007; Tantrarungroj, 2008). Media components incorporated to an OLE should predominantly be interactive.

\subsection{Dimensions of Online Learning}

Researchers are interested in student behavior and attitudes towards online learning, and some have already begun to report on classroom experiences that utilize one or more forms of educational technology. Four dimensions have been identified and can be used to better understand students' motivation and attitudes toward online learning. These dimensions are: affect, attitudes, intrinsic and extrinsic motivation (Saade et al., 2011). Research has also shown that positive attitudes and motivation toward online learning increases long term retention of knowledge significantly (Naidr et al., 2004).

\subsubsection{Affect}

Affect refers to the individual feelings of joy, gladness, resentment, discontent, revulsion, etc. toward a specific behavior (Saade et al., 2007). Positive affect towards technology leads to positive and enhanced learning experiences as well as increased self-efficacy; conversely, negative affect creates the tendency to avoid the use of technology and thereby limits or blocks the added value of technology as a curricular support mechanism (Arkkelin, 2003; Saade et al., 2007).

\subsubsection{Attitudes}

The well-established theory of reasoned action identifies attitude as one of the primary indicators of behavioral intention. Research literature that focused on attitudes toward technology has shown that student attitudes are deterministic in the level of learning they achieve via technology (Saade et al., 2010; Sunal et al., 2003). In addition, research conducted to confirm this claim has extended the discussion to include online learning environments as well (Daley et al., 2001; 
Saade, 2007; Saade and Galloway, 2005; Saade et al., 2009).

\subsubsection{Intrinsic and extrinsic motivation}

Researchers investigated the perspectives of motivation to better understand students' behavioral intentions toward the use of technology so as to predict whether a certain form of technology will be accepted or rejected. Intrinsic and extrinsic motivation have been identified as the key factors for behavioral intentions toward the use of technology (Saade et al., 2007).

Therefore it follows that:

Desirable Characteristic 3: The four dimensions of online learning, namely affect, attitudes, intrinsic and extrinsic motivation, can be used to better understand students' attitudes toward online learning (Saade et al., 2011). Positive attitudes and motivation toward online learning has been shown to increase long term retention of knowledge significantly (Naidr et al., 2004). An ideal OLE makes use of affect, attitudes, intrinsic and extrinsic motivation to create a positive attitude in facilitators and learners.

\subsection{Type of learning experience}

A number of studies concentrated on the manipulation of various elements within online learning and examined the effects of learning experience and learners' control. These studies recommend providing a form of learner control over the online sources-resources being utilized.

Gao and Lehman (2003), Zhang (2005), Zhang et al. (2006), and Dinov et al. (2008); present data that supports the hypothesis that instructor-directed conditions (expository learning) have less control over learning than the conditions in which learners have direct control (may it be interactive or active learning within the conceptual framework); direct control of learners tend to produce greater gains in learning. Two other studies did not succeed in finding a similar effect (Smith, 2006; Cook et al., 2007).

Zhang (2005) and Zhang et al. (2006), present two studies that distinguished between active learning versus expository learning, these two studies found outcomes that favored active learning. To generate the two situations Zhang (2005) controlled the performance within a web based course. There were particular orders for the control group regarding the videos being utilized, which they received over the web; they had to view any video in their entirety i.e. rewinding and fast forwarding the video was not allowed and it had to be seen wholly. The treatment group on the other hand was not restricted in this regards; they could watch the videos in any arrangement, access materials randomly, fastforward or rewind any video and go through the content however they pleased. Significantly positive results were found by that favored the control of learners over the functionality of web i.e. the treatment group (Zhang et al., 2006).

Gao and Lehman (2003) discovered that students who viewed only static web pages did not perform as good as the students who completed a "generative activity" along with viewing a static Web page. In the same way, Dinov, Sanchez and Christou (2008) incorporated apparatus from an online resource for statistical computations in three courses of statistics and probability. Two groups were created for each course and were compared. One of the groups obtained a high intensity situation and had access to numerous online tools to apply on facts and figures while the other group obtained a low intensity situation with limited access to online tools. In the three courses from all sections, students from the high intensity situation with active online tools showed significant improvement in results and understanding, as shown by the mid-term and final exams when in comparison to the other students.

The studies that discovered optimistic outcomes for non-didactic and learner controlled designs of teaching are balanced by the studies that discovered null or combined outcomes from attempts to give an additional in action learning know-how. Smith (2006) used randomly allocated groups of nurses who were trained online on pain management; he changed the instructional method in order to distinguish between an instructional method with participant inquiry and problem solving and a text-based expository linear method; in terms of learning, no significant differences were found. Likewise, no significant differences were found by Cook et al. (2007) in student learning between the following two situations: (1) expository end-of-module actions and (2) active response end-of-module review questions.

Chen (2007) randomly assigned the students of a health care ethics class to any one of the web-based situations given below on a random basis, (1) an experimental group that examined a text-based improved organizing tool prior to online guidelines, (2) a control group that obtained online instructions with no entry to an improved organizing tool and (3) another experimental group that evaluated an improved, Flash-based concept map organizing tool before getting involved into online learning. The researchers assumed that the concept map and improved organizing tool would assist 
students in accessing appropriate previous information and boost up their commitment with the latest material. Surprisingly, no specific differences in the learning outcomes were found by Chen among the three groups.

Suh (2006) studied the consequences of an assisting question on the capability of student to generate a high-class educational website needed for an online educational technology module. Students in this situation were given questions via an electronic discussion board, which they had to read first before answering. Online postings and electronic mails made them think of the assisting questions during their work in the problem situation. Assisting questions helped the students, who were working alone by enhancing their performance; however these questions did not in any way affect the performance of students working in teams. A likely clarification presented by the researcher is that students working in teams might have scaffolded the work of each other and might have reduced the benefit obtained by externally imparted questions.

Therefore it follows that:

Desirable Characteristic 4: An ideal OLE supports different types of learning experiences, such as purely online vs. mixed (Means et al., 2010) or instructor-directed conditions (expository learning) vs. direct control of learners (Gao and Lehman, 2003; Zhang, 2005; Zhang et al., 2006; and Dinov et al., 2008).

\subsection{Online quizzes}

Regarding the effectiveness of including quizzes into online learning, there are both optimistic and not so optimistic results. For instance, mixed outcomes were found by the four studies (Tselios et al., 2001; Lewis, 2002; Maag, 2004; Stanley, 2006) that investigated the effectiveness of online quizzes.

Maag (2004) and Stanley (2006) discovered no added benefits for the inclusion of online quizzes. Maag (2004) incorporated online quizzes in an experimental situation wherein the students were given animation, online images and texts; then this experimental group was evaluated against other groups that varied in terms of incorporating online quizzes as well as how media tools was used in the quizzes (one used text only, and one used images only, and one used both text and images). The researcher discovered no major differences among the groups that did not use online quizzes and the one that used online quizzes, or in terms of how media tools were employed. Similarly, Stanley (2006) discovered no statistically significant differences between the outcomes from students taking weekly quizzes and the outcomes from students completing regular homework assignments.

According to two additional studies the effectiveness of quizzes on learning depends on the existence of dynamic factors (Lewis, 2002) like the coexistence of online discussions with online quizzes. Interactivity within dynamic online discussions among students enhances learning and decreases the probability of failure within online quizzes that are less compelling without online discussions. It is suggested by Tselios et al. (2001) that performance of students is also affected by the software platform used to conduct online quizzes. It was found that students taking quizzes on the software platform known as IDLE (an open source learning management system) were outperformed with statistical significance by the students who took the quiz in WebCT (now known as the Blackboard Learning Management System) software platform. The two software programs had identical educational material and functioned similarly, but they had differences in user interfaces.

Grant and Courtoreille (2007) examined the utilization of post-unit quizzes (a) that provided students with the opportunity to do extra practice on the type of items that were not answered correctly and (b) with fixed items that gave response only on the correct or incorrect answer. Greater changes from the pre-test to post-test results indicated that the response-sensitive version of the tutorial was less effective than the fixed-item version.

Therefore it follows that:

Desirable Characteristic 5: An ideal OLE provides online quizzes at the end of each unit and gives feedback on the results (Grant and Courtoreille, 2007).

\subsection{Customized instruction}

The outcomes of employing computer-based instruction in a customized manner has been explored within this literature review with the intention that the online learning addresses vigorously to the performance, questions and needs of the participant. For instance, the meta-analysis by Kulik et al. (1991) reported that computer assisted instruction reduces instructional time on average by at least one third; efficiency in time management is especially vital for those nontraditional students who need to create a balance between schooling, home life, and employment. 
Nguyen (2007) investigated the outcomes of customized instruction and presented positive results. The researcher studied the encounters of individuals enrolled in tax preparation course. These individuals studied within an online training program and had the option of customizing their training by utilizing an advanced set of features that were context sensitive and included expert systems such as textual an audiovisual component integrated to tutorials. Nguyen (2007) indicated a positive effect resulting in statistically significantly higher outcomes as a result of this blend of enhancement.

Therefore it follows that:

Desirable Characteristic 6: An ideal online learning should be customizable and adaptive in order to suit the diverse needs of learners (Kulik, 1991, Nguyen, 2007).

\subsection{Assistance for learner reflection}

Nine studies examined the extent to which encouraging facets of learner reflection in a Web-based environment enhanced the results of learning (Chung et al., 1999; Cook et al., 2005; Wang et al., 2006; Chang, 2007; Crippen et al., 2007; Nelson, 2007; Saito et al., 2007; Shen et al., 2007; and, Bixler, 2008). These studies investigated OLE's that prompted the students to reflect on their learning and presented enhanced results due to such prompts. For instance, how computer prompts developed to promote students to utilize self-monitoring and self-explanation strategies influenced learning, was examined by Chung et al. (1999); they studied the capability of students to incorporate views from instructions in their writing tasks. The researchers discovered that students in the control group elaborated and incorporated statistically significantly less number of concepts than the students who were guided by computer prompts.

Wang et al. (2006), in a quasi-experimental study of students from a Taiwanese middle school acquiring a biology module based on the web, discovered that students using traditional testing (conducted in paper-pencil form or online) did not perform as well as the students employing seminal online self-evaluation approaches. In the seminal online evaluation situation, if an answer was incorrect, the student was told that it was wrong and was provided with extra resources to look for the correct answer, without actually providing the correct solution. This discovery supports the findings of Grant and Courtoreille (2007) explained previously.

Cook et al. (2005) examined the impact of the inclusion of "self-evaluation" queries towards the end of modules on the learning of students i.e. whether or not such queries enhanced learning. The research employed crossover, organized and randomized exam structures, wherein every student studied four courses, two with and two without selfevaluation questions. The course sequence was allocated on a random basis and the tests were conducted immediately at the end of the course. The students performed statistically better on tests that had self-evaluation questions, than on tests that did not have self-evaluation questions. The author attributed this outcome to the stimulation of reflection. However, this outcome did not appear for the final test administered at the end of the course, where the performance of every student was similar.

Shen et al. (2007) examined the work of students who did and did not obtain lectures on self-regulated learning approaches such as self-evaluation, dealing with study-time and goal-setting. The group that was subject to lectures on self-regulated approaches performed significantly better.

Bixler (2008) studied the consequences of prompts inquiring students to reflect on their problem-solving activities. Crippen and Earl (2007) examined the consequences of presenting prompts to describe a student's work along with examples of problems and solutions. Chang (2007) employed a self-examining outline for students so that they could evaluate their learning environments, study-times, and learning processes, and later on generate self-assessments and predict their test results. Saito and Miwa (2007) looked into the outcomes of students' manifestation activities during and after online learning sessions. A learning assistance system added by Nelson (2007) was developed to guide a hypothesis generation and testing process exclusive of providing straight responses about the correctness of a student's answer or creating decisions regarding the actions of a student. The extra reflective components described in all these studies enhanced students' online learning.

On the whole, the evidence available from research suggests that self-control, self-reflection and self-regulation create better learning effects. Traits like self-explanation, self-control and prompts for reflection approaches have been shown to enhance online learning results.

Therefore it follows that:

Desirable Characteristic 7: For an online environment traits like self-explanation, self-control and prompts for reflection approaches have been shown to enhance learning results (Chung et al., 1999; Cook et al., 2005; Wang et al., 2006; 
Chang, 2007; Crippen et al., 2007; Nelson, 2007; Saito et al., 2007; Shen et al., 2007; and Bixler, 2008). An ideal OLE provides assistance for learner reflection.

\subsection{Scaffolding for online learning}

Scaffolding, the support given during the learning process which is tailored to the needs of the student, helps the student achieve his/her learning goals (Sawyer, 2006). Several studies examined human control substituted by online scripts or scaffolding developed to create a more dynamic online communication. Of the four studies analyzed, three studies suggested that the existence of scaffolding to assist communication between groups that learn online does not have a direct significant enhancement over learning outcomes (Hron et al. 2000; Choi et al., 2005; Ryan 2007). However, the study by Weinberger et al. (2005) suggested the opposite.

An experimental method was used by Hron et al. (2000) to draw a contrast between three groups: (1) a group that obtained managing questions and argumentative guidelines, (2) a control group that obtained no guidelines about onehour argument and (3) a group that obtained managing questions to assist in developing their online communication. Argumentative guidelines specify that the group members should only talk about the managing questions; the argument regarding one question should be completed before starting the next question; the alternative point of views should be taken into consideration and lastly all members should take turns in moderating the argument and make sure all the rules and guidelines are followed to the letter. Hron et al. discovered statistically significant differences among situations in the material and consistency of student postings, but no crosswise differences between the three groups regarding acquisition of knowledge as indicated by the results of a multiple-choice test.

Ryan's study (2007) also drew the same conclusion as that of Hron et al. (2000). He hypothesized that the performance of students would be affected when exposed to collaborative tools. Ryan distinguished between two groups of students from middle school exposed to online learning: a control group with no access to collaborative tools and an experimental group where communication with peers and teachers was enabled and students had access to collaborative tools. Ryan discovered no statistically significant differences in terms of online educational performance between the two groups.

A time-series control-group analysis was employed by Choi, Land and Turgeon (2005) to examine the outcomes of presenting online scripts for creating questions to colleagues throughout group based online discussions. Even though scripts were discovered to enhance the number of questions asked, they did not influence the learning outcomes and quality of the questions asked.

On the other hand, Weinberger et al. (2005) conducted a study which revealed positive results for learners who were provided with scaffolding. The authors developed two kinds of scaffolding: (1) social scaffolding organized in such a way that students communicate among each other via techniques like information gathering through asking crucial questions and (2) epistemic scripts that stated the manner in which learners should advance in an allocated assignment and assisted learners to address specific issues. In this research the authors discovered that social scaffolding enhances test performance in contrast to a control group that took part in online discussions without any scaffolding; and, the results were statistically significant.

In short, methods like scripts or scaffolds for online communication between student groups have been discovered to have positive effects on the manner in which students interact with the online content and with each other, but there is no evidence discovered that this indeed enhances learning directly. However, it must be noted that, indirectly, peer to peer communication contributes to cooperative learning which has been proven to have positive effects on learning exploiting the collective knowledge and the synergy among the learners (Adami-Bunyard et al., 1998; Bernero, 2000).

Therefore it follows that:

Desirable Characteristic 8: Scaffolding, the support given during the learning process which is tailored to the needs of the student, helps learners achieve their learning goals (Sawyer, 2006) and may result in enhanced test performance (Weinberger et al., 2005). An ideal OLE provides scaffolding for online learning.

\subsection{Medium of delivery}

Online learning can be delivered predominantly through a mobile environment, the World Wide Web or via email; research has shown no considerable differences in learning resulting from the medium of delivery. For instance, Shih (2007) examined if student groups who viewed online contents with the help of mobile phones showed considerably diverse learning results from groups who did so utilizing a conventional computer with Internet access; no statistical 
differences were discovered between the two groups by the researcher. In the same way Kerfoot (2008) differentiated between the outcomes of obtaining module content and knowledge with the help of a sequence of e-mails versus viewing the content online through a conventional Web-site and discovered no statistically significant differences in terms of student learning. On the whole, the few controlled studies that explored how online content is delivered do not favor one method of delivery over another.

Therefore it follows that:

Desirable Characteristic 9: Online learning can be delivered through a mobile environment, the World Wide Web or via email; research has shown no considerable differences in learning resulting from the medium of delivery (Shih, 2007; Kerfoot, 2008). An ideal OLE is accessible anywhere, 24/7, as long as mobile and/or internet technologies are available.

\subsection{Distance learning}

Bernard et al. (2004) discovered benefits of asynchronous distance learning via online delivery over synchronous learning. Asynchronous distance-education studies by the authors presented advantages over traditional teacher centered classroom education. The authors also discovered that the distance-learning situations inclined to have further encouraging results when computer-mediated interactions were available.

Advantages of mixed learning (a combination of some features of face-to-face and online learning) over completely online learning were discovered by Zhao et al. (2005). It was discovered by Zhao et al. that the involvement of teacher plays the role of a powerful arbitrating variable. The impact of distance learning with high teacher involvement was significantly greater than that with low teacher involvement. Furthermore, Zhao et al. found that the effect size increased even further with the presence of peer-to-peer learning. In all cases, the use of digital resources enhanced the learning experience with statistical significance.

Therefore it follows that:

Desirable Characteristic 10: Distance-learning situations enhance the learning experience significantly when digital resources such as computer-mediated interactions are available (Bernard et al., 2004). An ideal OLE enables distance learning through learning activities that are interactive.

\subsection{Cooperative learning}

Cooperative learning approaches can be integrated to elevate students' motivation to learn math and enhance their math abilities. With the utilization of such approaches, students develop the necessary social skills required to complete the given projects. Cooperative learning also supports within group communication regarding the allocated tasks, wherein every member shares accountability for the work done both at the individual and the group levels as a whole. The employment of cooperative learning produces more awareness in mathematics and creates a pleasant experience for the teacher and the students. Integration of cooperative learning permits people to enjoy the group's collective knowledge of math and gain knowledge from others in order to enhance the overall learning experience (Bernero, 2000).

In the action research document by Adami-Bunyard et al. (1998), a set of courses that employ cooperative learning techniques were studied. The researchers documented the behavior of cooperative learning among primary school students where the participants enjoyed a peer-centered learning experience built upon rubrics and self-made exams. The researchers emphasized the significance of mentoring, tutoring and peer-tutoring; the instructions should be directed to the students and teacher should perform the role of a facilitator. With such approaches, it is likely that a bond is created among students when they work together ultimately increasing their academic success through an improved educational experience (Adami-Bunyard et al., 1998).

Therefore it follows that:

Desirable Characteristic 11: Integration of cooperative learning permits people to enjoy the group's collective knowledge and gain knowledge from others in order to enhance the overall learning experience (Bernero, 2000). An ideal OLE enables and supports cooperative learning.

\subsection{Addressing multiple intelligences}

Howard Gardner $(1985,1993)$ identified seven distinct intelligences (linguistic, logical-mathematical, bodily-kinesthetic, 
spatial, musical, interpersonal intrapersonal) that each person possesses a unique blend of. This has created the idea of teaching and learning through multiple intelligences (Campbell et al., 1996). The idea that modern day students are inclined towards using technology and Internet is the basis for employing technology as a means to assist teaching. Students of this century are much different from those of the last century; they live in the dynamism of the 21st century where Internet and other technologies advance in an ever increasing pace. In this regard technology can easily be integrated to the classrooms to address different learning styles as well as multiple intelligences (McCoog, 2007).

Interventions were implemented by Bednar et al. (2002) for the enhancement of achievement and motivation of students in mathematics by educating to multiple intelligences. According to the researchers, hardships faced by students with math concepts were due to negative attitudes of students toward the subject and their incapability to develop links between the real world and math. The researchers concluded that permitting students to utilize their early knowledge and multiple intelligences develops a meaning of tenure in the educational experience, which ultimately enhances mathematical knowledge and skills (Bednar et al., 2002).

Therefore it follows that:

Desirable Characteristic 12: Technology can be integrated to the classrooms to address different learning styles that correspond with multiple intelligences (McCoog, 2007). Permitting students to utilize their early knowledge and multiple intelligences develops a meaning of tenure in the educational experience, which ultimately enhances knowledge and skills (Bednar et al., 2002). An ideal OLE addresses multiple intelligences by making use of and providing different learning styles.

\subsection{Conforming to the state-wide and national educational standards}

The No Child Left Behind Act (NCLB, 2001) supports standards-based education reform in the U.S., based on the idea that setting high standards and establishing quantifiable goals are likely to improve individual student outcomes in education. NCLB requires states to develop standardized criterion referenced assessment tests that measure basic skills and administer them to all students in certain grades every year, if those states are to receive federal funding for schools. These yearly standardized tests are a major part of the research used to determine whether or not schools are living up to the standards that they are required to meet (Linn, 2000; Braden, 2002). If these standards are not met, the schools face decreased funding, salary cuts, job losses, and/or the state taking over a school district's administration, along with other punishments that contribute to the increased liability brought by the NCLB. Therefore, any OLE that aims to provide curricular support for the U.S. K-12 educational system needs to be aligned with state and nationwide learning standards, which includes the Common Core Standards. This necessity can be extended to any country that operates within standards-based curricula.

Therefore it follows that:

Desirable Characteristic 13: An ideal OLE conforms to educational standards. Any OLE that aims to provide curricular support for an educational system needs to be aligned with the standards associated with it. For instance in the U.S. K12 educational system, an OLE needs to be aligned with the Common Core State Standards.

\subsection{Fidelity of Implementation}

An OLE which works wonders in a certain setting may not live up to the expectations of another setting if it is not implemented at high levels of fidelity. The National Center on Response to Intervention defines fidelity of implementation this way: "It is the delivery of content and instructional strategies in the way in which they were designed and intended to be delivered: accurately and consistently. Although interventions are aimed at learners, fidelity measures focus on the individuals who provide the instruction." (National Center on Response to Intervention, n.d.).

According to Fixsen (2006), it is imperative for educators to comprehend that implementation is a mission-oriented process involving multiple decisions, actions, and corrections. This definition puts educators in an active role. They must consciously look at how a program is conducted in their schools and then make adjustments as needed. Wallace et al. (2008) specifically connected implementation to student learning indicating that improved outcomes in education are the product of effective innovations and effective implementation efforts.

Therefore it follows that:

Desirable Characteristic 14: An OLE must be implemented with fidelity for producing the results it has been designed to produce. Thus, the OLE must come with guidelines on how to make the most of it, i.e. how to implement it within 
different settings.

\subsection{The Need for Professional Development}

Lindstrom and Speck (2004) defined that professional development as a "lifelong, collaborative learning process that nourishes the growth of individuals, teams, and the school through a daily, job-embedded, learner-centered, focused approach". Professional development in the context of education generally refers to the ongoing learning opportunities made available to teachers and other education personnel, through their schools and districts. Professional development has two specific goals: 1) to meet the needs of the participants (teachers), and 2) to improve student learning and success (Stiles et al., 2009). Thus professional development is of utmost significance in order to achieve high levels of implementation fidelity.

Therefore it follows that:

Desirable Characteristic 15: In order for an OLE to be successful, it must be implemented withy fidelity and for this to happen, the facilitators must know how to use the OLE intimately. Thus, the OLE must come with online and/or offline professional development modules such as tutorials, seminars, webinars, etc.

\subsection{Adopting of new instructional paradigms}

In view of the changing and constantly increasing demands for e-learning, Greiner et al. (2004) claim that educators needs to develop new instructional paradigms in order to effectively meet the needs of learners. There are examples of innovative instructional models which support efficient knowledge construction in a web-based environment enabling long-term knowledge retention.

Therefore it follows that:

Desirable Characteristic 16: An OLE must possess the flexibility to adopt new and useful instructional paradigms as they emerge.

\section{Conclusion}

This literature review concentrated on one central theme; the desirable characteristics of an OLE. In summary, an ideal OLE uses computer tutorials and online learning activities; uses multimedia elements, simulations and manipulatives in an interactive way; uses the dimensions of online learning to create positive attitudes in learners; supports different types of learning experiences; provides online quizzes and gives feedback on the results; enables customized and adaptive instruction; provides assistance for learner reflection; provides scaffolding for online learning; is accessible anywhere, anytime; enables distance learning through interactive online learning activities; supports cooperative learning; addresses multiple intelligences; conforms to educational standards; provides guidelines for high fidelity of implementation in diverse settings; provides online and offline professional development modules; and is flexible to adopt new and useful instructional paradigms fast as they emerge.

\section{References}

Adami - Bunyard, E., Gummow, M., \& Milazzo - Licklider, N. (1998). Improving primary student motivation and achievement in mathematics.

Aivazidis, C., Lazaridou, M., and Hellden, G. (2006). A comparison between a traditional and an online environmental educational program. Journal of Environmental Education, 37(4), 45-54.

Arkkelin, D. (2003). Putting Prometheus' feet to the fire: Student evaluations of Prometheus in relation to their attitudes towards and experience with computers, computer self-Efficacy and preferred learning style. Retrieved February 22, 2011, from http://faculty.valpo.edu/darkkeli/papers/syllabus03.htm

Battle, T. (2007). Infusing math manipulatives: The key to an increase in academic achievement in the mathematics classroom. Final research proposal. Online Submission, Retrieved January 6, 2010, from ERIC database.

Bednar, J., Coughlin, J., Evans, E., \& Sievers, T. (2002). Improving student motivation and achievement in mathematics through teaching to the multiple intelligences. (ERIC Document Reproduction Service No. ED466408). Retrieved April 11, 2009 from http://www.eric.ed.gov/

Bernard, R. M., P. C. Abrami, Y. Lou, E. Borokhovski, A. Wade, L. Wozney, P. A. Wallet, M. Fiset, and B. Huang. (2004). How does distance education compare with classroom instruction? A meta-analysis of the empirical literature. Review of Educational 
Research 74 (3): 379-439.

Bernero, J. (2000). Motivating students in math using cooperative learning. (ERIC Document Reproduction Service No. ED446 999).

Bixler, B. A. (2008). The effects of scaffolding student's problem-solving process via question prompts on problem solving and intrinsic motivation in an online learning environment. PhD diss., The Pennsylvania State University, State College, Penn.

Braden, J. P. (2002). Best practices for school psychologists in educational accountability: High-stakes testing and educational reform. In A. Thomas \& J. Grimes (Eds.), Best practices in school psychology IV (Vol. 1, pp. 301-320). Bethesda, MD: National Association of School Psychologists.

Campbell, L., Campbell, B., \& Dickinson, D. (1996). Teaching \& learning through multiple intelligences. Needham Heights, MA: Allyn \& Bacon.

Castaneda, R. (2008). The impact of computer-based simulation within an instructional sequence on learner performance in a Webbased environment. PhD diss., Arizona State University, Tempe.

Chang, M. M. (2007). Enhancing Web-based language learning through self-monitoring. Journal of Computer Assisted Learning 23 (3): 187-96.

Chen, B. (2007). Effects of advance organizers on learning and retention from a fully Web-based class. PhD diss., University of Central Florida, Orlando.

Choi, I., S. M. Land, and A. J. Turgeon. (2005). Scaffolding peer-questioning strategies to facilitate metacognition during online small group discussion. Instructional Science 33 (5-6): 483-511.

Chung, S., M. -J. Chung, and C. Severance. (1999, October). Design of support tools and knowledge building in a virtual university course: Effect of reflection and self-explanation prompts. Paper presented at the WebNet 99 World Conference on the WWW and Internet Proceedings, Honolulu, Hawaii. (ERIC Document Reproduction Service No. ED448706).

Clark, R. E. (1983). Reconsidering research on learning from media. Review of Educational Research 53 (4): 445-49.

Clark, R. E. (1994). Media will never influence learning. Educational Technology Research and Development 42 (2): 21-29.

Cook, D. A., D. M. Dupras, W. G. Thompson, and V. S. Pankratz. (2005). Web-based learning in residents' continuity clinics: A randomized, controlled trial. Academic Medicine 80 (1): 90-97.

Cook, D. A., M. H. Gelula, D. M. Dupras, and A. Schwartz. (2007). Instructional methods and cognitive and learning styles in Web-based learning: Report of two randomized trials. Medical Education 41 (9): 897-905.

Crippen, K. J., and B. L. Earl. (2007). The impact of Web-based worked examples and self-explanation on performance, problem solving, and self-efficacy. Computers and Education 49 (3): 809-21.

Daley, B. J., Watkins, K., Williams, S. W., Courtenay, B., Davis, M., \& Dymock, D. (2001). Exploring learning in a technology-enhanced environment. Educational Technology \&Society, 4(3), 126-138.

Dinov, I. D., J. Sanchez, and N. Christou. (2008). Pedagogical utilization and assessment of the statistic online computational resource in introductory probability and statistics courses. Computers and Education 50 (1): 284-300.

Fixsen, D. L. (2006). Implementing evidence-based education. Presentation to OSEP Project Directors' Conference. Retrieved from The National Implementation Research Network Web site: www.fpg.unc.edu/ nirn/resources/presentations/OSEP_Mtg_Fixsen_ HO.pdf

Fouts, J. T. (2000). Research on computers and education: Past, present, and future. Seattle, WA: Bill and Melinda Gates Foundation.

Gao, T., and J. D. Lehman. (2003). The effects of different levels of interaction on the achievement and motivational perceptions of college students in a Web-based learning environment. Journal of Interactive Learning Research 14 (4): 367-86.

Gardner, H. (1985). Frames of mind: The theory of multiple intelligences. Basic books.

Gardner, H. (1993). Multiple intelligences: The theory in practice. Basic books.

Grant, L. K., and M. Courtoreille. (2007). Comparison of fixed-item and response-sensitive versions of an online tutorial. Psychological Record 57 (2): 265-72.

Greiner, C., Serdyukov, P., Subbotin, I. \& Serdyukova, N. (2004). Enhancing E-learning Outcomes Through Iteration. In J. Nall \& R. Robson (Eds.), Proceedings of World Conference on E-Learning in Corporate, Government, Healthcare, and Higher Education 2004 (pp. 1225-1228).

Handal, B., and Herrington, A. (2003). Re-examining categories of computer-based learning in mathematics education. Contemporary Issues in Technology and Teacher Education, 3(3), 275-287.

Hron, A., F. W. Hesse, U. Cress, and C. Giovis. (2000). Implicit and explicit dialogue structuring in virtual learning groups. British Journal of Educational Psychology 70 (1): 53-64.

Inan, F. A., Lowther, D. L., Ross, S. M., \& Stahl, D. (2010). Pattern of classroom activities during students' use of computers: Relations between instructional strategies and computer applications. Teaching \& Teacher Education, 26(3), 540-547.

Kerfoot, B. P. (2008). Interactive spaced education versus Web-based modules for teaching urology to medical students: a randomized controlled trial. The Journal of Urology 179 (6): 2351-57.

Kulik, C.-L. and Kulik, J. A. (1991). Effectiveness of computer-based instruction: An updated analysis. Computers in Human Behavior, $7(1-2), 75-94$.

Kulik, J. A. (2002). School mathematics and science programs benefit from instructional technology - InfoBrief (Report No. NSF-03301). Arlington, VA.: National Science Foundation, Div. of Science Resources Statistics.

Lewis, B. A. (2002). The effectiveness of discussion forums in online learning. Brazilian Review of Open and Distance Learning 1 (1), http: //www. abed. org. br/publique/cgi/cgilua. exe/sys/start. htm?infoid=16andsid=73andUserActiveTemplate=1por (accessed March 5, 2009). 
Lindstrom, P., \& Speck, M. (2004). The Principal as Professional Development Leader. Thousand Oaks, CA: Corwin.

Linn, R. L. (2000). Assessments and accountability. Educational Researcher, 29, 4-16.

Loar, R. S. (2007). The impact of a computer simulated case study on nurse practitioner students' declarative knowledge and clinical performance. PhD diss., University of Illinois at Urbana-Champaign.

Luo, L., \& O'Leary, D. M. (2005). Axon retraction and degeneration in development and disease. Annual Review of Neuroscience, 28, 127-56.

Maag, M. (2004). The effectiveness of an interactive multimedia learning tool on nursing students' math knowledge and self-efficacy. Computers, Informatics, Nursing 22 (1): 26-33.

Marzano, R. J., Pickering, D. J., \& Pollock, J. E. (2004). Classroom instruction that works: Research-based strategies for increasing student achievement. Upper Saddle River, NJ: Prentice Hall.

McCoog, I. J. (2007). Integrated Instruction: Multiple Intelligences and Technology. Clearing House 81(1), 25-28.

McKethan, R. N., M. W. Kernodle, D. Brantz, and J. Fischer. (2003). Qualitative analysis of the overhand throw by undergraduates in education using a distance learning computer program. Perceptual and Motor Skills 97 (3 Pt. 1): 979-89.

Naidr J.P., Adla T., Janda A., Feberova J., Kasal P., Hladikova M. (2004) Long-Term Retention of Knowledge After a Distance Course in Medical Informatics at Charles University Prague. Teaching and Learning in Medicine;16(3):255-9.

National Center on Response to Intervention (n.d.). RTI practices glossary. Retrieved from www.rti4success.org/index.php? option=com_content\&task=view\&id=634\&ltemid=2

Nelson, B. C. (2007). Exploring the use of individualized, reflective guidance in an educational multi-user virtual environment. Journal of Science Education and Technology 16 (1): 83-97.

Nelson, B., \& Sassi, A. (2007). What math teachers need most. Education Digest: Essential Readings Condensed for Quick Review, 72(6), 54-56.

Nguyen, F. (2007). The effect of an electronic performance support system and training as performance interventions. PhD diss., Arizona State University, Tempe.

No Child Left Behind (NCLB) Act of 2001. Pub. L. No. 107-110, Psychology H.R. 1, 115 Stat. 1425.

Ryan, R. (2007). The effects of Web-based social networks on student achievement and perception of collaboration at the middle school level. PhD diss., Touro University International, City, Calif.

Saade, G. R., M. D. Buyukkurt, C. Alkhori. (2011). Technology Mediated Learning: Observations in Two Technologies. Issues in Informing Science \& Information Technology Vol. 8, p398

Saade, G. R. (2007). Dimensions of perceived usefulness: Towards enhanced assessment. Decision Sci-ences Journal of Innovative Education, 5(2), 289-310.

Saade, G. R., \& Galloway, I. (2005), Understanding the acceptance of multimedia applications for learning. Issues in Informing Science and Information Technology, 2, 287-296. Retrieved from http://2005papers.iisit.org/l23f15Saad.pdf

Saade, G. R., \& Huang, Q. (2009). Meaningful learning in discussion forums: Towards discourse analysis. Issues in Informing Science and Information Technology, 6, 87-99. Retrieved from http://iisit.org/Vol6/IISITv6p087-099Saade675.pdf

Saade, G. R., Nebebe, F., \& Mak, T. (2010). Knowledge management systems development: Theory and practice. Interdisciplinary Journal of Information, Knowledge and Management, 6, 35-72. Retrieved from http://www.ijikm.org/Volume6/IJIKMv6p035072Saade472.pdf

Saade, G. R., Nebebe, F., \& Tan, W. (2007). Viability of "Technology Acceptance Model" in multimedia learning environments: A comparative study. Interdisciplinary Journal of Knowledge and Learning Objects, 3, 175-184. Retrieved from http://www.ijello.org/Volume3/IJKLOv3p175-184Saade393.pdf

Saade, R. G., He, X., \& Kira, D. (2007). Exploring dimensions to online learning. Computers in human behavior, 23(4), 1721-1739.

Saade, R. G., M. D. Buyukkurt, C. Alkhori. (2011). Technology Mediated Learning: Observations in Two Technologies. Issues in Informing Science \& Information Technology Vol. 8, p398

Saito, H., and K. Miwa. (2007). Construction of a learning environment supporting learners' reflection: A case of information seeking on the Web. Computers and Education 49 (2): 214-29.

Salimpoor, V. N., Chang, C., \& Vinod, M. (2010). Neural basis of repetition priming during mathematical cognition: Repetition suppression or repetition enhancement? Journal of Cognitive Neuroscience, 22(4), 790-805.

Sawyer, R. K. (Ed.). (2006). The Cambridge Handbook of the Learning Sciences (Vol. 2, No. 5). Cambridge: Cambridge University Press.

Schmeeckle, J. M. (2003). Online training: An evaluation of the effectiveness and efficiency of training law enforcement personnel over the Internet. Journal of Science Education and Technology 12 (3): 205-60.

Schnitman, I. (2007). The dynamics involved in Web-based learning environment (WLE) interface design and human-computer interactions $(\mathrm{HCl})$ : Connections with learning performance. PhD diss., West Virginia University, Morgantown.

Schroeder, B. A. (2006). Multimedia-enhanced instruction in online learning environments. PhD diss., Boise State University, Boise, Idaho.

Schutt, M. (2007). The effects of instructor immediacy in online learning environments. PhD diss., University of San Diego and San Diego State University, San Diego, Calif.

Shen, P. D., T. H. Lee, and C. W. Tsai. (2007). Applying Web-enabled problem-based learning and self-regulated learning to enhance computing skills of Taiwan's vocational students: A quasi-experimental study of a short-term module. Electronic Journal of eLearning 5 (2): 147-56. 
Shih, Y. E. (2007). Dynamic language learning: Comparing mobile language learning with online language learning. PhD diss., Capella University, Minneapolis, Minn..

Sivin-Kachala, J., \& Bialo, E. R. (2000). Research report on the effectiveness of technology in schools, 7th ed. Washington D.C: Software \& Information Industry Association.

Smith, C. M. (2006). Comparison of Web-based instructional design strategies in a pain management program for nursing professional development. PhD diss., State University of New York at Buffalo.

Stanley, O. L. (2006). A comparison of learning outcomes by 'in-course' evaluation techniques for an online course in a controlled environment. The Journal of Educators Online 3 (2): 1-16.

Stiles, K. E., Loucks-Horsley, S., Mundry, S., \& Hewson, P. W. (Eds.). (2009). Designing professional development for teachers of science and mathematics. Corwin Press.

Suh, S. (2006). The effect of using guided questions and collaborative groups for complex problem solving on performance and attitude in a Web-enhanced learning environment. PhD diss., Florida State University, Tallahassee.

Sunal, D. W., Sunal, C. S., Odell, M. R., \& Sundberg, C. A. (2003). Research-supported best practices for developing online learning. Journal of Online Interactive Learning, 2(1).

Tamim, R. M., Bernard, R. M., Borokhovski, E., Abrami, P. C., \& Schmid, R. F. (2011). What forty years of research says about the impact of technology on learning a second-order meta-analysis and validation study. Review of Educational Research, 81(1), 428.

Tantrarungroj, P. (2008). Effect of embedded streaming video strategy in an online learning environment on the learning of neuroscience. PhD diss., Indiana State University, Terre Haute.

Tselios, N. K., N. M. Avouris, A. Dimitracopoulou, and S. Daskalaki. (2001). Evaluation of distance-learning environments: Impact of usability on student performance. International Journal of Educational Telecommunications 7 (4): 355-78.

Waite-Stupiansky, S., and Stupiansky, N. (1998). Math in action: Hands-on, minds-on math. Instructor, 108(3), 85. Retrieved January 6 , 2010, from ERIC database.

Wallace, F., Blase, K., Fixsen, D., \& Naoom, S. (2008). Implementing the findings of research: Bridging the gap between knowledge and practice. Alexandria, VA: Educational Research Service.

Wang, K. H., T. H. Wang, W. L. Wang, and S. C. Huang. (2006). Learning styles and formative assessment strategy: Enhancing student achievement in Web-based learning. Journal of Computer Assisted Learning 22 (3): 207-17.

Weinberger, A., B. Ertl, F. Fischer, and H. Mandl. (2005). Epistemic and social scripts in computer supported collaborative learning. Instructional Science 33 (1): 1-30. [Two studies are reported. ]

Zhang, D. (2005). Interactive multimedia-based e-learning: A study of effectiveness. American Journal of Distance Education 19 (3): 149-62.

Zhang, D., L. Zhou, R. O. Briggs, and J. F. Nunamaker, Jr. (2006). Instructional video in e-learning: Assessing the impact of interactive video on learning effectiveness. Information and Management 43 (1): 15-27.

Zhao, Y., J. Lei, B. Yan, C. Lai, and H. S. Tan. (2005). What makes the difference? A practical analysis of research on the effectiveness of distance education. Teachers College Record 107 (8). 
